\title{
Capsaicin in the Treatment of Refractory Neuropathic Pain after Mastectomy Surgery: A Case Report
}

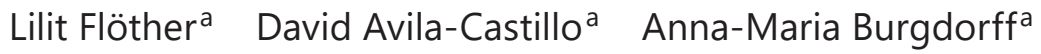 \\ Ralf A. Benndorf ${ }^{b}$

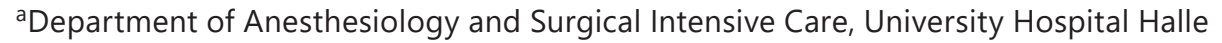 \\ (Saale), Halle (Saale), Germany; ${ }^{b}$ Department of Clinical Pharmacy and Pharmacotherapy, \\ Martin Luther University Halle-Wittenberg, Halle (Saale), Germany
}

Keywords

Pain · Capsaicin · Mastectomy $\cdot$ Neuropathic pain

\begin{abstract}
A 62-year-old female patient with a history of mastectomy surgery and sentinel lymphadenectomy in the context of breast cancer therapy was referred to our clinic for the treatment of refractory neuropathic pain. She reported a complex set of symptoms including burning and electrical-like sensations as well as profound hyperesthesia, hyperalgesia, and allodynia. The symptoms persisted chronically over months with a strong intensity and did not sufficiently respond to oral pain medication and co-analgetics, that is, tapentadol and pregabalin. As the patient could hardly move her right upper arm due to the pain, the quality of life was greatly reduced. In addition, the patient reported pain-related anxiety and depression. Therefore, a therapy with capsaicin $8 \%$ patch was initiated. Treatment with capsaicin $8 \%$ led to pain relief without tolerance development and improved flexibility in the affected body area. Despite significant pain relief, previous oral pain medications (tapentadol, pregabalin) as well as the anti-depressant amitriptyline were maintained to fully resolve pain symptoms, anxiety, and depression. In conclusion, capsaicin $8 \%$ may represent an effective therapeutic alternative for patients suffering from refractory neuropathic pain.

\section{Introduction}

Neuropathic pain has several definitions, the most accepted being pain caused by a lesion or affection of the somatosensory system including peripheral and central neurons [1]. Neuropathic pain is a major health burden, commonly associated with diseases such as diabetes 
mellitus or cancer, and may arise, for example, in the context of surgical treatment of oncological diseases. Since improvement of quality of life is a crucial target in the treatment of cancer patients, powerful therapies and novel therapeutics targeting neuropathic pain are urgently needed. In line with this notion, neuropathic pain is associated with increasing drug prescriptions and consultations of health care providers. With better understanding of underlying pathophysiology of neuropathic pain, novel therapeutic strategies and diagnostic procedures as well as personalized interventions are made available to the patient. There are numerous therapeutic recommendations for treatment of neuropathic pain including different drugs, such as pregabalin (gamma-aminobutyric acid [GABA] analogue), gabapentin (inhibition of voltage-dependent calcium channels), duloxetine (serotonin-noradrenaline reuptake inhibitor), as well as various tricyclic antidepressants, that are strongly recommended as first-line treatments for peripheral and central neuropathic pain [2]. As a second-line treatment for peripheral neuropathic pain, capsaicin 8\% (the active component of chili peppers) and lidocaine patches as well as tramadol (a low-potency opioid with additional serotonin and noradrenaline reuptake inhibitory actions) have been proposed [3, 4]. However, the evidence for the treatment of refractory tumor-associated pain with high-dose capsaicin patch systems is still very limited.

\section{Case Presentation}

A 62-year-old female patient, $164 \mathrm{~cm}$ tall and weighing $62 \mathrm{~kg}$, presented with a medical history of treated breast cancer, first diagnosed in 2010. After standard treatment of breast cancer including surgery (mastectomy and axillary lymph node dissection) followed by radiochemotherapy, the patient was referred in April 2014 to a multidisciplinary team for treatment of refractory neuropathic pain. Since 2010, the patient had suffered from permanent, motiondependent, pulling, burning pain in the right chest area (scar after mastectomy) and on the inside of the right upper arm with radiation into the entire right shoulder. In addition, numbness of the affected area and the entire right chest was detected.

At the presentation in April 2014, the patient reported pain in the area of the scar (chest) and the right arm. Hyperalgesia, hyperesthesia, and allodynia (lesion of the right brachial plexus after ablatio mammae) were also documented. The allodynia ranged from the scar area to the axilla and the right medial upper arm. The pain was persistent and reached a pain intensity of 7-7.5/10 Numeric Pain Rating Scale (NPRS) without treatment, but increased with movement and then reached NPRS values of 8-9/10. Due to the severe pain with pronounced allodynia and sensitivity of the skin, an examination of the affected areas was hardly possible. The patient could hardly move the right upper arm due to the pain, the quality of life was greatly reduced. In addition, normal coping with everyday life was no longer possible due to the poor night's sleep caused by pain and psycho-emotional overload. The general well-being was also clearly impaired. In addition, a questionnaire on depression and anxiety (HADS, Hospital Anxiety and Depression) revealed signs of existing depression and anxiety. There were no concomitant diseases.

\section{Pain Treatment}

Since 2010, the patient has received a drug therapy consisting of pregabalin and amitriptyline. The NPRS remained at 5/10 under therapy. In April 2014, the pregabalin dose was therefore initially increased and treatment with tapentadol was started in May 2014, the dose of which also had to be increased in the course of the treatment (shown in Table 1). However, the neuropathic pain and the neurological plus and minus phenomena, which were very stressful for the patient, remained resistant to therapy and the drug therapy did not show sufficient efficacy for more than 4 months. 
Table 1. Course, dose, and success of drug therapy

\begin{tabular}{|c|c|c|c|}
\hline Initiation of therapy & Therapy & Dose, mg & Therapeutic effect \\
\hline 2010 & $\begin{array}{l}\text { Pregabalin } \\
\text { Amitriptyline }\end{array}$ & $\begin{array}{l}150-0-300 \\
0-0-75\end{array}$ & NRS 5/10 \\
\hline $\begin{array}{l}\text { April } 2014 \\
\text { (first presentation) }\end{array}$ & $\begin{array}{l}\text { Pregabalin } \\
\text { Amitriptyline } \\
\text { Duloxetine }\end{array}$ & $\begin{array}{l}300-0-300 \\
0-0-75 \\
30-0-0\end{array}$ & $\begin{array}{l}\text { Discontinued by patient } \\
\text { due to intolerance }\end{array}$ \\
\hline May 2014 & $\begin{array}{l}\text { Pregabalin } \\
\text { Amitriptyline } \\
\text { Tapentadol }\end{array}$ & $\begin{array}{l}300-0-300 \\
0-0-75 \\
50-0-50 \text {, increased from the } \\
\text { third day on } 100-0-100\end{array}$ & $\begin{array}{l}\text { NRS } 5 / 10 \\
\text { Initiation of therapy due } \\
\text { to severe pain }\end{array}$ \\
\hline July 2014 & $\begin{array}{l}\text { Pregabalin } \\
\text { Amitriptyline } \\
\text { Tapentadol }\end{array}$ & $\begin{array}{l}150-0-150 \\
0-0-75 \\
150-0-150\end{array}$ & $\begin{array}{l}\text { Dose increase due to } \\
\text { persistent pain }\end{array}$ \\
\hline $\begin{array}{l}\text { September } 2014 \\
\text { (begin capsaicin 8\%) }\end{array}$ & $\begin{array}{l}\text { Capsaicin } 8 \% \\
\text { Pregabalin } \\
\text { Amitriptyline } \\
\text { Tapentadol }\end{array}$ & $\begin{array}{l}1 \text { patch; } 30 \text { min } \\
150-0-150 \\
0-0-50 \\
150-0-150\end{array}$ & $\begin{array}{l}\text { NRS 3-4/10 } \\
\text { Hyperesthesia } \downarrow \\
\text { Allodynia } \downarrow \downarrow \downarrow\end{array}$ \\
\hline Since August 2015 & $\begin{array}{l}\text { Capsaicin } 8 \% \\
\text { Pregabalin } \\
\text { Amitriptyline } \\
\text { Tapentadol }\end{array}$ & $\begin{array}{l}1-2 \text { patches; } 30 \text { min; every } \\
\text { third month, } \\
18 \text { treatments in total } \\
150-0-150 \\
0-0-50 \\
150-0-150\end{array}$ & \\
\hline
\end{tabular}

\section{Treatment with Capsaicin 8\%}

Treatment with the capsaicin 8\% patch was first performed in September 2014, initially with one patch for 30 min (shown in Figs. 1 and 2). From April 2015, further capsaicin 8\% treatments followed every 3 to 6 months. Due to the large pain area, the dose was adjusted from August 2015 to up to two patches according to the current symptoms on the respective treatment day. Before capsaicin 8\% was applied, a 30-min treatment with a topical anesthetic (4\% lidocaine gel, additionally containing menthol) and subsequent cooling for a further 30 min was carried out. Hydromorphone $(2.6 \mathrm{mg}$ ) was provided when needed by the patient.

\section{After Treatment with Capsaicin 8\%}

Outcome of capsaicin 8\% therapy resulted in a slight improvement in pain (NPRS 3-4/10) and an improvement in hyperesthesia, hyperalgesia, and, in particular, allodynia within the first 8 weeks. There were no side effects. After 8 to 9 weeks, however, the intensity of pain increased again and finally reached previous levels, which is why capsaicin $8 \%$ was applied again after 12 weeks. The oral pain medication of the patient was continued in parallel due to the strong and permanent pain, but could be reduced in the course of therapy (shown in Table 1: dose of pregabalin and amitriptyline). Due to existing depression and neurological complaints, no further dose reduction of amitriptyline was made.

\section{Course of Therapy}

To date (February 2020) a total of 18 applications with the $8 \%$ capsaicin patch have been carried out without any tolerance development. Therapy response and patient satisfaction were good and quality of life was improved. The patient reported that dressing and undressing had become easier. In addition, night sleep had improved, as had the psychoemotional 


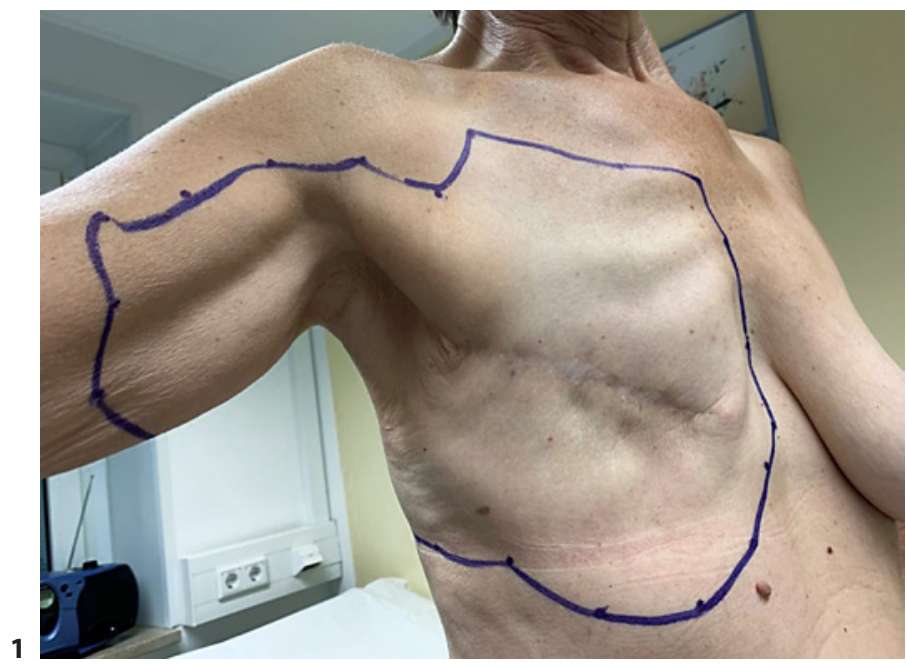

Fig. 1. Area for the application of the $8 \%$ capsaicin patch in the range of the right chest area: marking on the patient.

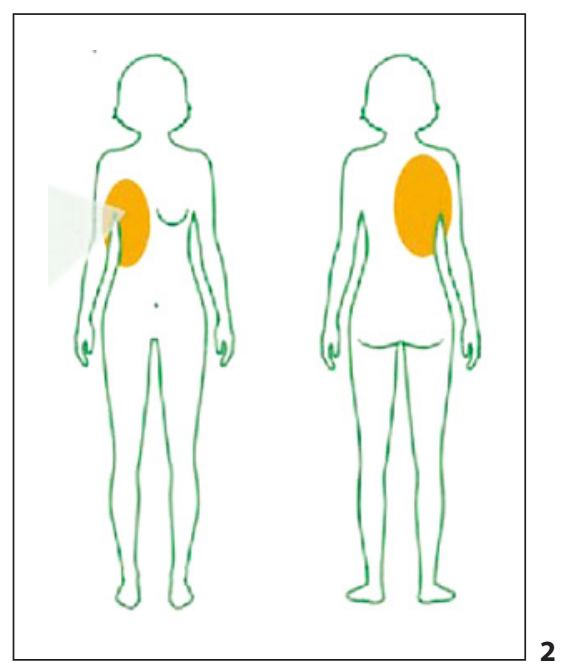

Fig. 2. Area for the application of the $8 \%$ capsaicin patch in the range of the right chest area: schematic representation of the entire treatment area.

component: the patient felt psychologically stable and the relationship with her husband was improved. She was also able to travel extensively (e.g., in a camper van with her husband for 3 to 4 months in Spain). The tolerability and satisfaction with the application were very high.

\section{Discussion}

In this case report, local therapy with capsaicin (trans-8-methyl-N-vanillyl-6-nonenamide) was administered to resolve a post-mastectomy pain syndrome that severely limited the patient's quality of life. The treatment led in particular to an improvement of the neuropathic symptoms hyperesthesia and allodynia as well as to a slight relief of the pain. In addition, capsaicin $8 \%$ improved the mobility of the right arm and was able to contribute to a lasting improvement in the quality of life and a reduction in the accompanying pain medication thanks to its long-lasting and low-tolerance efficacy.

Neuropathic pain can significantly impair quality of life and is often associated with further problems, such as limited mobility, disturbed sleep, anxiety, and depression [5]. Successful treatment of these comorbidities is therefore of great importance for the overall success of therapeutic interventions. To date and to our knowledge, however, only very little data is available on the efficacy of high-dose capsaicin therapy in patients with residual pain symptoms after cancer treatment, although the treatment of neuropathic pain in these patients is a particular challenge due to the complexity and diversity of symptoms. Most of the findings on the efficacy of high-dose capsaicin in chronic neuropathic pain syndromes have been collected in patients with post-herpetic neuralgia, HIV polyneuropathy, and diabetic neuropathy [6]. However, our observations may add to the available information that oncological patients with difficult-to-control neuropathic pain could particularly benefit from high-dose capsaicin possibly due to the complementary pharmacodynamic action profile of the drug. In this regard, local capsaicin exerts its effects via transient receptor potential vanilloid 1 (TRPV1) activation and subsequent desensitization in the cutaneous area of the application area [7]. This particular pharmacodynamics of capsaicin also has clear disadvan-

\section{Karger'}


tages, as it can only be used under strictly controlled conditions, often after local anesthesia, because of the initial intense burning sensation it causes [7]. Nevertheless, in most clinical studies, capsaicin was associated with good tolerability. However, systematic clinical trials are needed to substantiate the potential benefit of capsaicin in this patient group.

\section{Conclusion}

Taken together, this case report indicates that local capsaicin as well as an effective multidisciplinary cooperation between gynecologists, anesthetists, and physiotherapists are able to facilitate successful treatment and rehabilitation of patients suffering from refractory neuropathic pain in the context of cancer therapy.

\section{Statement of Ethics}

Written informed consent to publish the case and the included pictures was obtained from the patient. Institutional consent is available.

\section{Conflict of Interest Statement}

The authors have no conflicts of interest to declare.

\section{Funding Sources}

The University and State Library of the Martin Luther University Halle-Wittenberg supports open access publications with a publication fund to finance the publication fees.

\section{Author Contributions}

L.F. helped manage the patient, conduct the background research, and write the manuscript. R.B. helped write the manuscript. A.-M.B and D.A.-C. helped care for the patient and helped write the manuscript.

\section{References}

1 Murnion BP. Neuropathic pain: current definition and review of drug treatment. Aust Prescr. 2018;41(3):60-3.

2 Attal N, Cruccu G, Baron R, Haanpää M, Hansson P, Jensen TS, . EFNS guidelines on the pharmacological treatment of neuropathic pain: 2010 revision. Eur J Neurol. 2006;17(9):1113-e88.

3 Backonja M, Wallace MS, Blonsky ER, Cutler BJ, Malan P Jr, Rauck R, . NGX-4010, a high-concentration capsaicin patch, for the treatment of postherpetic neuralgia: a randomised, double-blind study. Lancet Neurol. 2008;7(12): 1106-12.

4 Bates D, Schultheis BC, Hanes MC, Jolly SM, Chakravarthy KV, Deer TR, . A comprehensive algorithm for management of neuropathic pain. Pain Med. 2019;20(Suppl 1):S2-S12.

5 Finnerup NB, Attal N, Haroutounian S, McNicol E, Baron R, Dworkin RH, . Pharmacotherapy for neuropathic pain in adults: a systematic review and meta-analysis. Lancet Neurol. 2015;14(2):162-73.

6 Derry S, Sven-Rice A, Cole P, Tan T, Moore RA. Topical capsaicin (high concentration) for chronic neuropathic pain in adults. Cochrane Database Syst Rev. 2013;(2):CD007393.

7 Fattori V, Hohmann MS, Rossaneis AC, Pinho-Ribeiro FA, Verri WA. Capsaicin: current understanding of its mechanisms and therapy of pain and other pre-clinical and clinical uses. Molecules. 2016;21(7):844-76.

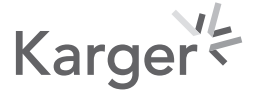

